\title{
A QUESTÃo da NATUREZa hUMANA: KANT LEITOR DE ROUSSEAU
}

\author{
Joel Thiago Klein ${ }^{1}$
}

Resumo: Este artigo analisa a influência da filosofia de Rousseau na teoria antropológica de Kant. No primeiro momento, apresentam-se as semelhanças e diferenças acerca do modo como cada autor compreende o estado de natureza. No segundo momento, estabelece-se uma comparação entre o conceito de sociabilidade insociável de Kant e os conceitos de piedade e amor próprio, na filosofia de Rousseau.

Palavras-Chave: Kant. Rousseau. Antropologia. Natureza humana.

É bastante paradigmática a afirmação de Kant acerca de Rousseau, encontrada em uma reflexão datada de 1764-1765, quinze anos antes da publicação da Crítica da razão pura:

Eu sou por inclinação um pesquisador. Sinto uma grande sede por conhecimento, uma ansiada inquietação em avançar mais em sua direção e também felicidade quando alcanço algum. Havia um tempo em que eu pensava que apenas isso poderia trazer glória à humanidade e eu desprezava o povo que náo sabia de nada. Rousseau me trouxe ao caminho correto. Aquela preferência cega desapareceu e eu aprendi a honrar os homens. Eu me sentiria sem finalidade, como um trabalhador indigno, se eu náo acreditasse que aquelas reflexóes poderiam atribuir algum valor para estabelecer os direitos da humanidade. (KANT, Bemerkungen zu den Beobachtung über das Gefühl des Schönen und Erhabenen, AA 20: 44. 8-16, traduçáo nossa). ${ }^{2}$

\footnotetext{
${ }^{1}$ Professor de Filosofia na Universidade Federal de Santa Catarina (UFSC), Florianópolis, SC - Brasil. iD https://orcid.org/0000-0003-2665-9113 E-mail: jthklein@yahoo.com.br

Bolsista Produtividade CNPq (2). O presente trabalho foi realizado com apoio da Coordenação de Aperfeiçoamento de Pessoal de Nível Superior (Capes) - Brasil, Código de Financiamento 001. Finalmente, este artigo também recebeu apoio da Alexander von Humboldt Stiftung.

${ }^{2}$ Cito as obras de Kant conforme as regras da Akademie Ausgabe (AA). Utilizo as seguintes siglas que correspondem as seguintes obras: Ia $G=$ Ideia de uma história universal com um propósito cosmopolita;

http://dx.doi.org/10.1590/0101-3173.2019.v42n1.02.p9
} 
Essas afirmaçóes expressivas conduzem inevitavelmente a consideraçóes sobre em que medida e de que forma a obra de Rousseau exerceu influência na obra do filósofo alemão. Em outra reflexão do mesmo período, lê-se:

Newton viu pela primeira vez a ordem e a regularidade unidas com grande simplicidade onde antes dele se encontrava desordem e uma desagradável e redobrada diversidade, e desde entáo os cometas percorrem órbitas geométricas. Rousseau descobriu pela primeira vez, sob a diversidade das formas humanas convencionais, a profunda e oculta natureza do homem e a escondida lei, de acordo com a qual a providência, através das suas observaçōes, é justificada. (KANT, Bemerkungen zu den Beobachtung über das Gefühl des Schönen und Erhabenen, AA 20: 58f. 12-01, tradução nossa).

A comparação entre Rousseau e Newton é digna de destaque, seja pelo grande reconhecimento que Newton já havia angariado, na época, seja pela admiração que Kant abertamente lhe conferia. A descoberta de Rousseau atinge dois aspectos: de um lado, a "profunda e oculta natureza do homem"; por outro, a "escondida lei", cuja semelhança com a formulação crítica da "lei moral", fundamento da ética e do direito, não se tem dificuldade em perceber. ${ }^{3}$

O reconhecimento da importância da antropologia kantiana trouxe consigo inúmeras questôes de coerência sistemática, especialmente no que se refere

$M A M=$ Início conjectural da história humana; Anth = Antropologia de um ponto de vista pragmático; $\mathrm{V}$-Anth/Fried $=$ Liçôes de antropologia anotadas segundo o estudante Friedländer; $K U=$ Critica da faculdade do juizo; KpV= Crítica da razão prática; $M S=$ Metafisica dos costumes; $Z e F=$ À paz perpétua; WDO $=O$ que significa orientar-se no pensamento; Refl = Reflexöes .

${ }^{3}$ Nesse sentido, ver, por exemplo, as seguintes afirmaçōes do Contrato social: "Encontrar uma forma de associação que defenda e proteja com toda a força comum a pessoa e os bens de cada associado, e pela qual cada um, unindo-se a todos, só obedeça, contudo, a si mesmo e permaneça táo livre quanto antes" (ROUSSEAU, 1999, p. 20 / III, 360). Ou ainda: "À aquisiçẫo do estado civil a liberdade moral, a única que torna o homem verdadeiramente senhor de si mesmo, porquanto o impulso do mero apetite é escravidão, e a obediência à lei que se prescreveu a si mesmo é liberdade." (ROUSSEAU, 1999, p. 26 / III, 365). Ou ainda, no Emílio: "Depois de ter assim, da impressấo dos objetos sensíveis e do sentimento interior que me leva a julgar as causas conforme as minhas luzes naturais, deduzido as principais verdades que me importava conhecer, resta-me procurar saber que máximas devo prescrever a mim mesmo para cumprir minha destinação aqui na terra, conforme a intenção daquele que aqui me colocou. Continuando a seguir o meu método, não extraio essas regras dos princípios de uma alta filosofia, mas encontro-as escritas no fundo do coraçáo, escritas pela natureza em caracteres indeléveis." (ROUSSEAU, 2014, p. 404 / IV, 594). As citaçôes aos textos de Rousseau são feitas a partir das traduçóes para a língua portuguesa cotejadas com os textos em língua francesa. Por essa razão, nas referências, indicam-se inicialmente os dados das traduçóes utilizadas e, após a barra, o volume e a página das Oeuvres complètes de Rousseau, publicadas pela Editora Gallimard. 
à relação entre a parte empírica e a parte pura da filosofia kantiana. ${ }^{4}$ Isso, por sua vez, inevitavelmente conduz a pesquisa para a investigação da própria história do desenvolvimento de algumas teses antropológicas. Retomando as duas passagens citadas acima, isso significa dizer que é inevitável e imprescindível entender $o$ quanto e em que sentido Rousseau indicou a Kant o caminho correto, não apenas na questão da fundamentação da lei moral, mas também a respeito da forma como entender a antropologia e os problemas que surgem, quando se tenta integrar uma teoria moral com uma teoria antropológica e cultural.

Esse vínculo entre ambos os autores pode ser visto inclusive no modo como eles definem a natureza humana e o estudo da antropologia. Rousseau abre o seu Discurso sobre as ciências e as artes com as seguintes palavras:

É um espetáculo grandioso e belo ver o homem sair, por seu próprio esforço, a bem dizer do nada; dissipar, por meio das luzes de sua razão, as trevas nas quais o envolveu a natureza; elevar-se acima de si mesmo; lançar-se, pelo seu espírito, às regiôes celestes; percorrer com passos de gigantes, como o sol, a vasta extensão do universo; e, o que é ainda maior e mais difícil, penetrar em si mesmo para estudar o homem e conhecer sua natureza, seus deveres e seu fim. (ROUSSEAU, 1973, p. 341s / III, 6).

Nessa passagem, encontram-se vários elementos importantes. Primeiramente, vem à tona a consideração de que estudar o homem e conhecer a sua natureza é algo que envolve um trabalho muito maior e demanda muito mais esforço do que conhecer a vasta extensão do universo. Ele volta a esse pensamento no final do discurso, ao reafirmar que "a verdadeira filosofia" está em "voltar-se para si mesmo e ouvir a voz da consciência no silêncio das paixôes.” (ROUSSEAU, 1973, p. 360 / III, 30). O segundo aspecto é que estudar a natureza do homem significa estudar aquilo que ele fez de si próprio, pois o homem saiu por seu próprio esforço a bem dizer do nada. $\mathrm{O}$ caráter ativo e histórico se torna assim uma característica intrínseca da antropologia rousseauniana, sendo que o homem "se faz a si próprio", através de uma complexidade de atos, muitos dos quais inconscientes ou náo planejados, mas que são sempre ainda ações suas. Com isso, há o rompimento com uma tradição que concebia o homem de uma forma essencialmente metafísica, de maneira que os traços do caráter humano seriam sempre os mesmos, desde o início dos tempos. Isso representa uma separação da visão política aristotélica, segundo

\footnotetext{
${ }^{4}$ Os estudos, nesse sentido, receberam maior impulso na Kant-Forschung, com a publicação das Liçôes sobre antropologia, editadas em 1997 por Reinhard Brandt e Werner Stark, em dois volumes, as quais se referem ao volume 25 da Akademie Ausgabe.
} 
a qual o homem era definido como um animal político. ${ }^{5}$ Em outras palavras, enquanto, para Aristóteles ou para a tradição aristotélico-tomista, a vida social era uma continuaçấo e um desdobramento natural da vida do homem, que começa com a família e alcança a polis, para Rousseau, toda a política, assim como toda a vida social são frutos da arte, isto é, são elementos artificiais acrescentados sobre a natureza humana.

De modo bastante semelhante, na Antropologia de um ponto de vista pragmático, lê-se:

Para indicar a classe do ser humano no sistema da natureza viva e assim o caracterizar, nada mais nos resta a não ser afirmar que ele tem um caráter que ele mesmo cria para si mesmo enquanto é capaz de se aperfeiçoar segundo os fins que ele mesmo assume; por meio disso, ele, como animal dotado da faculdade da razáo (animal rationabile), pode fazer de si um animal racional (animal rationale). (KANT, Anth, AA 07: 321f). ${ }^{6}$

Note-se que, também para Kant, o homem é compreendido como uma criatura cuja singularidade está exatamente na capacidade de criar para si mesmo o seu caráter. Entende-se por caráter aquilo que constitui o homem enquanto tal, suas características distintivas e que são determinantes para a forma como age e vive. Nesse sentido, a própria razão não é vista como algo dado, algo que já atua corretamente por conta própria, tal como o instinto atua nos animais. A razão é uma disposição que precisa ser realizada através de disciplina e esforço. A forma como a razão atua depende do modo como ela conseguiu se educar, durante a sua história. Também aqui entra a historicidade como um elemento constitutivo da reflexão antropológica.

Seguindo-se essas indicaçôes acerca das relaçóes que se instauram entre a teoria antropológica de Rousseau e a de Kant, este artigo se desdobra em duas seçôes, as quais abordam os seguintes temas: a primeira estabelece uma comparação a propósito da caracterização do homem natural, enquanto a segunda analisa os sentimentos e inclinações que movimentam o agir humano, ao longo do processo histórico.

\footnotetext{
5 "A cidade é uma criação natural e que o homem é por natureza um animal social, e um homem que por natureza, e não por mero acidente, não fizesse parte de cidade alguma, seria desprezível ou estaria acima da humanidade [...] Agora é evidente que o homem, muito mais que a abelha ou outro animal gregário, é um animal social." (ARISTÓTELES, 1997, p. 15 / 1253a).

${ }^{6}$ Nas lições de antropologia ministradas nos anos de 1775/76, com relação ao tópico "Do caráter da humanidade em geral", Kant afirma: "Eis uma secçáo importante, sobre a qual já muitos autores ousaram escrever (o mais importante de todos Rousseau)." (KANT, V-Anth/Fried, AA 25.1: 675).
} 


\section{O HOMEM NATURAL}

Tanto para Rousseau quanto para Kant, acessar o passado primevo da espécie humana demanda a utilização de um procedimento conjectural. De acordo com Rousseau, as conjecturas se fazem necessárias, quando se pretende descrever acontecimentos que podem ter ocorrido de várias maneiras e aos quais não se pode escolher senão por meio de conjecturas, ou seja, "quando dois fatos dados como reais devem ser ligados por uma série de fatos intermediários, desconhecidos ou considerados como tais, cabe a história, se a temos, apresentar os fatos que os ligam; se não a temos, cabe à filosofia determinar os fatos semelhantes que podem ligá-los." (ROUSSEAU, 2013, p. 79 / III, 162s). Nesse sentido, as conjecturas a respeito do estado de natureza e da passagem para o estado civil se tornam razôes, "quando são as mais prováveis que se pode fazer sobre a natureza das coisas e os únicos meios que se pode ter para descobrir a verdade.” Tornar as conjecturas razóes significa assumir que, a partir delas, "não se poderia formar nenhum outro sistema que me fornecesse os mesmos resultados e do qual [se] pudesse tirar as mesmas conclusóes." (ROUSSEAU, 2013, p. 79 / III, 162). Assim, pode-se dizer que, conforme Rousseau, o procedimento conjectural ou hipotético busca preencher uma lacuna de compreensão entre o estado civil atual e o estado de natureza, uma compreensão que não possui o valor de verdade, mas possui o valor de "um bom argumento". Nesse contexto, o estado de natureza é uma construção teórica feita com base na análise e comparação entre a vida dos homens em diferentes continentes, bem como entre o homem e os animais (mediante reflexôes sobre anatomia comparada).

Mas qual o motivo desse procedimento? Garantir uma compreensão justa daquilo que é a natureza do homem e daquilo que lhe é artificial, ou seja, compreender que aquilo que é artificial poderia não ter sido e ocorrido de forma diferente. ${ }^{7}$ Segundo Rousseau, a caracterização antropológica que busca separar essas duas condiçóes, a natural e a civil, tem como consequência direta

\footnotetext{
7 "Que meus leitores não imaginem, portanto, que ouso enaltecer-me de ter visto o que me parece tăo difícil de ver. Iniciei alguns raciocínios, arrisquei algumas conjecturas, menos na esperança de resolver o estado da questáo do que na intenção de esclarecê-lo e de reduzi-lo a seu verdadeiro estado. Outros poderão seguir mais de longe no mesmo caminho, sem que seja fácil a ninguém chegar ao término. Pois não é um empreendimento ligeiro separar o que há de originário e artificial na natureza atual do homem e conhecer devidamente um estado que não existe mais, que talvez nunca tenha existido, que provavelmente nunca existirá, mas sobre o qual é necessário ter noçôes justas para avaliar bem o nosso estado presente." (ROUSSEAU, 2013, p. 34s / III, 123). "Comecemos, pois, por afastar todos os fatos, já que eles não tocam na questão. Não convém tomar as investigaçóes que podem ser feitas sobre esse tema como verdades históricas, mas apenas como raciocínios hipotéticos e condicionais, mais aptos a
} 
para a política e para a moral a abertura do campo do possível e, por conseguinte, para o campo para a crítica social, tópico ao qual se retornará adiante.

De maneira muito semelhante, Kant escreve:

Certamente é permitido mesclar conjecturas no desdobramento de uma história com a finalidade de preencher lacunas nas informaçôes, pois o que precede, como causa distante, e o que segue, como efeito, podem, para tornar concebível a passagem, oferecer uma direçáo consideravelmente segura na descoberta das causas intermediárias. Contudo, deixar que uma história surja totalmente e apenas a partir de conjecturas não parece ser muito melhor do que o projeto de escrever um romance. Além disso, ele não poderia levar o nome de uma história conjectural, mas de uma mera fição. - Entretanto, o que não se permite ousar no desdobramento da história do agir humano, bem pode ser tentado através de conjecturas em relação ao primeiro início mesmo, desde que a natureza o produza. Ora, náo se permite inventá-lo, mas ele pode ser tirado da experiência se se supóe que ela, no primeiro início, não era melhor nem pior do que como nós a encontramos agora: uma suposição que está de acordo com a analogia da natureza e não traz consigo nenhum risco. Uma história do primeiro desenvolvimento da liberdade a partir de sua disposição originária na natureza do homem é, por isso, algo completamente distinto da história da liberdade em seu desdobramento, a qual pode fundar-se apenas sobre informaçóes. (KANT, MAM, AA 08: 109).

Acerca dessa passagem, alguns comentários são necessários. Primeiro, é digno de nota que a utilização de conjecturas pode ser feita apenas para se pensar o primeiro início da história humana, isto é, para se pensar sobre o estado de natureza e a passagem ao estado civil, mas náo mais para se pensar a história da espécie humana. Nesse caso, Kant não tem em vista aqui uma crítica a Rousseau e ao seu segundo Discurso, pois este teria se restringido a pensar exatamente o primeiro início. O alvo da crítica de Kant parece ser aqui Herder, com quem, nesse período, Kant se envolve em uma disputa teórica. ${ }^{8}$ A história do desenvolvimento dos diversos povos somente pode ser objeto da historiografia e não de uma história conjectural. O segundo aspecto que precisa ser destacado é o de que o processo de realização de conjecturas não é meramente invenção criativa, contudo, precisa estar baseado no procedimento analógico pelo qual se supóe que a natureza, "no primeiro início, não era

esclarecer a natureza das coisas do que mostrar a sua verdadeira origem, e semelhantes aos que fazem os nossos físicos todos os dias sobre a formação do mundo." (ROUSSEAU, 2013, p. 45 / III, 132s).

8 Para uma caracterização mais detalhada sobre isso, ver meus artigos (KLEIN, 2012, 2013). 
melhor nem pior do que como nós a encontramos agora." Isso significa que a reflexão analógica demanda uma reconstrução do primeiro início, a partir de uma perspectiva de que o homem natural e o homem social não eram essencialmente diferentes, mas apenas gradativamente diferentes, ou seja, que todas as potencialidades que estão mais ou menos desenvolvidas agora já se encontravam no homem natural, mas apenas em gérmen ou, ainda, em estado embrionário. Entretanto, o inverso também pode ser verdadeiro, isto é, capacidades que agora estáo subdesenvolvidas poderiam ter estado mais desenvolvidas, como no caso do olfato ou da audição.

Se, para Kant, a caracterização do estado de natureza e sua passagem para o estado civil também constituem objeto de uma reflexão conjectural, a função teórica dessa descrição recebe, entretanto, uma nova conotação. Segundo ele, "não se permite que as pretensóes de aprovaçáo daquelas conjecturas cresçam demasiadamente, mas elas devem, quando muito, anunciar-se apenas como um exercício permitido da imaginação em companhia da razão para o descanso e saúde do ânimo e não como uma ocupação séria." (KANT, MAM, AA 08: 109). Essa asserção precisa ser lida com cuidado. A negação de seriedade se refere a dois aspectos: primeiro, que não se trata de um discurso que busque pretensão de verdade (nesse sentido, de modo semelhante a Rousseau), afinal, não se trata de uma descrição factual; segundo, que a história conjectural não tem o objetivo de servir como uma razão para se estabelecer um julgamento moral com relação a situação humana atual (distinguindo-se aqui de Rousseau). Conforme Kant, não são as conjecturas que servirão como critérios a fim de se fazer uma avaliação moral do estado presente da espécie humana, pois isso é uma competência exclusiva da reflexão moral que tem como critério a lei moral, uma representação criada a priori pela razão prática. Mas isso não significa que o início conjectural não possua uma finalidade prática, porque faz parte de uma visão moral do mundo que se opóe a outras visóes morais da história humana, as quais desresponsabilizam o homem pela sua condição, condenando-o, assim, a um estado de assujeitamento histórico. Em outras palavras, a caracterização do início conjectural se insere no contexto da filosofia kantiana da história no horizonte da criação de uma visão moral de mundo que permita ao ser humano manter a sua esperança de um contínuo progresso moral da espécie humana. ${ }^{9}$

Tendo em vista, então, o caráter conjectural, passa-se agora ao modo como cada filósofo concebia o homem natural. Rousseau supunha o homem

\footnotetext{
${ }^{9}$ Sobre a defesa dessa leitura, ver meu livro (KLEIN, 2016), especialmente o último capítulo.
} 
natural como "andando com dois pés, servindo-se das mãos como fazemos com as nossas, dirigindo o olhar a toda a natureza e medindo com os olhos a vasta extensão do céu." (ROUSSEAU, 2013, p. 47 / III, 134) Partindo disso, ele atribui ainda ao homem natural as seguintes características:

\title{
1. Animal solitário que tende a evitar a companhia de outros da mesma espécie e que se encontra apenas para acasalar; ${ }^{10}$
}

\section{Animal frugívoro e não carnívoro; ${ }^{11}$}

3. Animal forte e sagaz, que não possui nenhum instinto próprio, porém, que é capaz de se adaptar a ambientes e situaçôes, de modo que possui boas condiçóes de sobrevivência; ${ }^{12}$

\section{Animal que vive feliz e tranquilo; ${ }^{13}$}

\begin{abstract}
${ }^{10}$ Cf. "No estado primitivo, sem casas nem cabanas, nem propriedade de espécie alguma, cada um se abrigava em qualquer lugar e em geral por um a única noite; os machos e as fêmeas se uniam fortuitamente conforme o encontro, a ocasião e o desejo, sem que a palavra fosse um intérprete muito necessário das coisas que tinham a se dizer. Eles se deixavam com a mesma facilidade. A mãe aleitava inicialmente os filhos para sua própria necessidade, depois, afeiçoando-se a eles pelo hábito, passou a alimentá-los para a necessidade deles; os filhos, tão logo tinham a força de buscar seu alimento, não tardavam a deixar a mãe." (ROUSSEAU, 2013, p.61s. / III, 147). "Como a fome e outros apetites lhe faziam experimentar sucessivamente diversas maneiras de existir, houve uma que o convidou a perpetuar a sua espécie; e essa inclinaçáo cega, desprovida de todo sentimento de coração, não era senão um ator puramente animal. Satisfeita a necessidade, os dois sexos não se reconheciam mais, e o próprio filho nada mais significava para a mãe assim que podia passar sem ela." (ROUSSEAU, 2013, p. 81 / III, 164).

${ }^{11}$ Cf. "Assim, parece que o homem, tendo os dentes e os intestinos como os dos animais frugívoros, deveria naturalmente ser incluído nessa classe, e não apenas as observaçôes anatômicas confirmam essa opinião: os monumentos da antiguidade também são favoráveis a ela." (ROUSSEAU, 2013, p. 120 / III, 199).

${ }^{12}$ Cf. "Vejo um animal menos forte do que uns, menos ágil do que outros, mas, levando tudo em conta, organizado de modo mais vantajoso que os demais. [...] Dispersos entre eles [os animais], os homens observam, imitam seu engenho e elevam-se até o instinto dos animais, com a vantagem de que cada espécie tem apenas seu próprio instinto, enquanto o homem, não tendo nenhum que lhe pertença, apropria-se de todos, alimentando-se igualmente da maior parte dos alimentos diversos que os animais dividem entre si e, portanto, encontrando sua subsistência mais facilmente, como nenhum deles pode fazer." (ROUSSEAU, 2013, p. 48 / III, 135). "O homem selvagem, entregue pela natureza apenas ao instinto, ou melhor, talvez recompensado, na falta deste, por faculdades capazes de inicialmente substituí-lo, para em seguida elevá-lo muito acima delas, começará, portanto, pelas funçóes puramente animais." (ROUSSEAU, 2013, p. 57 / III, 142s).

${ }^{13}$ Cf. "Seus desejos não excedem suas necessidades físicas. Os únicos bens que conhece no universo são o alimento, uma fêmea e o repouso; os únicos males que teme são a dor e a fome” (ROUSSEAU, 2013, p. 57 / III, 143); "Sua alma, que nada agita, entrega-se apenas ao sentimento atual de sua existência, sem nenhuma ideia do futuro, por próximo que seja, e seus projetos, limitados como sua visão, mal se estendem até o fim do dia." (ROUSSEAU, 2013, p. 58 / III, 144). "Limitados apenas ao físico do amor, e bastante felizes por ignorar as preferências que irritam esse sentimento e aumentam as suas
\end{abstract}


5. Animal que desconhece o bem e o mal moral, mas se guia pelos sentimentos do amor de si e da piedade, de maneira que dificilmente causaria dano a outrem. ${ }^{14}$

Com essa caracterização do homem natural, coloca-se obviamente a questão de como foi possível, então, o surgimento da sociedade e de toda a desigualdade nela existente. Na segunda parte do segundo Discurso, Rousseau defende que essa desigualdade se estabeleceu a partir do surgimento da propriedade, a qual se torna, assim, o elemento-chave para se pensar a sociedade e o desenvolvimento da cultura. Mas a própria propriedade é uma ideia que demandou um certo tempo para ser adquirida, pois presume um grau de abstração que o homem natural não teria. É, por conseguinte, entre a condição do homem natural (entendida como "a infância" da humanidade) e a condição social (concebida como "a idade adulta" da espécie humana) que se deve buscar o surgimento e o desenvolvimento das ideias necessárias para o convívio social e o desenvolvimento da ideia de propriedade (no que se poderia denominar "idade da juventude"). Nesse processo, no que diz respeito ao objetivo deste artigo, duas consideraçôes são dignas de nota:

1. A conjectura da passagem da idade de infância para a idade da juventude se assenta exclusivamente sobre eventos contingentes, ${ }^{15}$ os quais não con-

dificuldades, os homens devem sentir com menos frequência e menos intensamente os ardores do temperamento e, por conseguinte, as disputas entre si devem ser mais raras e menos cruéis. A imaginação, que causa tanta devastação entre nós, não fala a coraçôes selvagens; cada um espera tranquilamente o impulso da natureza, entrega-se a ele sem escolha, com mais prazer do que furor, e, satisfeita a necessidade, todo o desejo se extingue." (ROUSSEAU, 2013, p. 74 / III, 158).

${ }^{14}$ Cf. "Os homens nesse estado, não tendo entre si nenhuma espécie de relação moral nem deveres conhecidos, não podiam ser nem bons nem maus e nấo tinham nem vícios nem virtudes.” (ROUSSEAU, 2013, p. 68 / III, 152). "Os selvagens não são maus, precisamente porque não sabem o que é ser bons, pois não é nem o desenvolvimento das luzes nem o freio da lei, mas a calma das paixōes e a ignorância do vício que os impede de fazer o mal." (ROUSSEAU, 2013, p. 69 / III, 154). "Colocado pela natureza a uma igual distância da estupidez dos brutos e das luzes funestas do homem civil, e limitando-se a proteger-se, pelo instinto e pela razão, contra o mal que o ameaça, ele é impedido pela piedade natural de fazer o mal a alguém sem ser forçado a isso por alguma coisa, mesmo tendo sofrido algum mal." (ROUSSEAU, 2013, p. 87 / III, 170).

${ }^{15}$ Cf. "À medida que o gênero humano se ampliou, os trabalhos se multiplicaram com os homens. A diferença das terras, dos climas, das estaçôes pôde força-los a incluí-la em sua maneira de viver. Anos estéreis, invernos longos e rudes, verôes abrasadores que consomem tudo exigiram deles uma nova indústria. Ao longo do mar e dos rios, inventaram a linha e o anzol, tornaram-se pescadores e ictiófagos. Nas florestas, construíram arcos e flechas e se tornaram caçadores e guerreiros. Nos países frios cobriram-se com as peles dos animais que matavam. O raio, um vulcão ou algum feliz acaso, lhes fez conhecer o fogo, novo recurso contra o rigor do inverno." (ROUSSEAU, 2013, p. 81 / III, 165). 
seguem explicar suficientemente a passagem de uma condição independente e isolada para uma relação de colaboração e vida em pequenos grupos, o que conduz ao questionamento da validade dessa conjectura;

2. O julgamento de Rousseau de que o referido estado intermediário ou de juventude era "o melhor para o homem, que só pôde abandoná-lo por algum funesto acaso que, para a utilidade comum, nunca devia ter acontecido." Afinal, "todos os progressos ulteriores foram, aparentemente, passos para a perfeição do indivíduo e, efetivamente, para a decrepitude da espécie." (ROUSSEAU, 2013, p. 88 / III, 171). Assim, embora Rousseau rejeite que o retorno para as florestas seja uma saída viável para a espécie humana ${ }^{16}$ (ao qual ainda fica em aberto, para alguns indivíduos), ${ }^{17}$ ele reconhece que aquele estado seria o melhor para a espécie.

Quando se compara a história hipotética de Rousseau com aquela apresentada por Kant, em seu Início conjectural da história humana, percebe-se tanto similitudes quanto diferenças. Com relação às similitudes, cabe destacar as seguintes:

1. Também Kant divide a primeira história em três épocas: infância (domínio do instinto), juventude (sociedades primitivas) e idade adulta (sociedade civil) (KANT, MAM, AA 08: 109-123);

2. Também para Kant o homem no estado de natureza, ou seja, enquanto vivia como um animal sob o domínio do instinto, náo poderia ser considerado nem bom, nem mau por natureza; ${ }^{18}$

\footnotetext{
${ }^{16}$ Cf. "Mas como! Então é preciso destruir as sociedades, aniquilar o que é meu e o que é teu e voltar a viver nas florestas com os ursos? Essa é uma consequência à maneira de meus adversários, que prefiro antecipar a deixar-lhes a vergonha de tirá-la." (ROUSSEAU, 2013, p. 133 / III, 207).

${ }^{17}$ Cf. "Ao mesmo tempo, sabemos de muitos franceses e outros europeus que se refugiaram voluntariamente entre essas naçôes e lá passaram a vida inteira, sem poder mais abandonar essa estranha maneira de viver; sabemos até de sensatos missionários que se sentem saudade dos dias calmos e inocentes que passaram entre esses povos tâo desprezados. Se responderem que eles não têm luzes suficientes para julgar corretamente sua condição e a nossa, replicarei que a avaliação de felicidade é menos uma questáo de razão do que de sentimento.” (ROUSSEAU, 2013, p. 153 / III, 220).

18 "Ora, ao evocarmos o estado da natureza, constatamos por certo que o [685] homem da natureza vive inicialmente mais feliz e, portanto, também mais inocente; mas só num sentido negativo ele é feliz e inocente, pois o seu estado não traz consigo nenhuma felicidade, mas também nenhuma infelicidade. $\mathrm{O}$ bem não é nele nenhum vício, nem nenhuma virtude. $\mathrm{O}$ positivo da felicidade e o positivo da virtude estão ausentes do estado natural. Neste estado, o homem é uma criança que nada pode fazer nem de bom, nem de mau. A perfeição negativa do estado de natureza consiste na ausência de miséria e de vício." (KANT, V-Anth/Fried, AA 25.1: 684f).
} 
3. Também Kant vê no desenvolvimento da razão e da sociedade, a qual tem como elemento central a ideia de propriedade, a fonte dos sacrifícios, males e sofrimentos produzidos pelo trabalho e pela discórdia entre os homens. ${ }^{19}$

Já com relação às diferenças, é importante ressaltar as seguintes:

1. O homem natural possui um instinto próprio e não "copiava" comportamentos dos outros animais. Nesse sentido, foi exatamente a contradição a esse instinto inicial que deu oportunidade à razão para "trapacear a voz da natureza" e tomar consciência da sua liberdade (KANT, MAM AA 08: 112);

2. Para Kant, o homem, mesmo no estado natural, não vivia isolado e sozinho, mas em pequenas estruturas familiares, ou seja, a visão antropológica kantiana concebe o homem como já dotado de uma sociabilidade natural, a qual não é algo que foi adquirido artificialmente ao longo da história (entretanto, Kant concorda com Rousseau de que o Estado seja uma construção artificial). ${ }^{20}$ É exatamente por isso que se pode pensar a possibilidade do desenvolvimento e perpetuação da linguagem, da arte e da técnica, entre as diferentes geraçóes e até mesmo da existência de um direito, algo que Rousseau tem grande dificuldade de explicar com sua hipótese monista-antropológica;

3. De acordo com Kant, a saída do homem da sua primeira morada, isto é, a passagem da rudeza de uma criatura meramente animal para a con-

${ }^{19}$ Cf. "Por isso, esse passo é ligado igualmente com a emancipação [Entlassung] do homem dos braços maternos da natureza: uma mudança que é ao mesmo tempo honrosa e cheia de perigos. A natureza lança o homem para fora do estado inofensivo e seguro da infância - como de um jardim onde vivia na comodidade e sem sacrifícios (v. 23) - e o impele ao grande mundo onde tantos problemas, sacrifícios e males desconhecidos o aguardam. No futuro, as dificuldades da vida farão com que ele frequentemente se sinta atraído pelo desejo de um paraíso, produto de sua imaginação, onde ele poderia sonhar ou despender seu tempo [115] em um descanso tranquilo e numa paz duradoura." (KANT, MAM, AA 08: 114f).

${ }^{20}$ Cf. "Se não se quer perder em conjecturas, entẫo o início precisa ser construído sob pressuposiçốes que a razão humana seja incapaz de derivar de causas naturais anteriores, a saber: com a existência do homem, e precisamente como um indivíduo já formado, pois ele precisa ser independente de subsídio materno; em um par, para que ele propague sua espécie; e, apenas um único casal, para que não surja imediatamente uma guerra, caso os homens estivessem próximos e todavia fossem estranhos uns aos outros, ou para que a natureza também nâo fosse culpada de ter deixado faltar, através da diversidade de ascendentes, uma organização destinada à sociabilidade como o fim mais alto da determinaçáo humana. Ora, a unidade da família, a partir de onde todos os homens deveriam se originar foi sem dúvida o melhor arranjo para essa questão." (KANT, MAM, AA 08: 110). 
dução da razão e o estado de liberdade, representa um ganho para a espécie humana, ainda que para o indivíduo possa ser uma perda, "uma queda". ${ }^{21}$

4. Para Kant, todo o processo histórico é conduzido segundo a ideia de um desenvolvimento teleológico, ou seja, da existência de gérmens que possuem em si mesmos um impulso para se desenvolver. Desse modo, tanto o desenvolvimento social que ocorreu no contexto do estado de natureza quanto a saída do estado de natureza e criação do Estado não são representados por Kant como resultados de situaçóes ou atos contingentes, mas como eventos atrelados naturalmente ao desenvolvimento das faculdades humanas, as quais possuem uma predisposição teleológica ao desenvolvimento, que inclusive está ancorado em um mandamento moral, como é a saída do estado de natureza e a entrada no estado civil. Assim, para Kant, não é possível representar nem antropológica nem moralmente a possibilidade de uma "estagnação" do processo de civilização, como sugere e lamenta Rousseau, pois para Kant esse desejo seria apenas uma ânsia vazia. Nas palavras de Kant:

Uma ânsia que táo fortemente estimula os Robinsons e as viagens para as ilhas dos mares do sul. [...] A vacuidade desses desejos de retornar àquela idade de simplicidade e inocência torna-se suficientemente visível quando se é instruído através da representação do estado originário acima: o homem não podia se manter em tal estado, [123] pois ele não lhe bastava; muito menos está disposto a retornar alguma vez a ele. Portanto, o homem sempre deve imputar a si mesmo e a sua própria escolha o atual estado de dificuldades. (KANT, MAM, AA 08: 122f).

Em suma, as estórias de robinsonadas não passam para Kant de romances idílicos que não constituem uma alternativa viável nem para a espécie humana (da mesma forma que para Rousseau), nem para o indivíduo (distintamente de Rousseau), pois essa seria uma alternativa que contradiz a visão teleológica e moral da história, da natureza e do homem. Segundo Weyand (1963, p. 80), seria exatamente por isso que não se poderia procurar uma filiação do conceito de antagonismo kantiano na obra de Rousseau, pois, em Kant,

\footnotetext{
${ }^{21}$ Cf. "Enquanto que para a espécie esse curso é um progresso do pior ao melhor, para o indivíduo não se pode dizer o mesmo. Antes do despertar da razão náo existia nenhum mandamento ou proibição e também nenhuma transgressão. Mas quando ela em sua ocupação começou, fraca como é, um conflito com toda força em relação à animalidade, entâo tiveram que nascer males e, o que é pior, em relação a uma razão cultivada, vícios, os quais eram totalmente alheios ao estado de ignorância e de inocência. Assim, o primeiro passo para fora daquele estado de natureza foi, da perspectiva moral, uma queda, cujas consequências físicas foram uma multiplicidade de males jamais conhecida em relação à vida, portanto, foi um castigo." (KANT, MAM, AA 08: 115).
}

${ }^{22}$ Sobre a ideia de robinsonada, ver também (KANT, KU AA 05:275f). 
essas tendências antagônicas (de isolamento ou de socialização) estão ligadas e subordinadas intrinsecamente na natureza humana, enquanto, para Rousseau, fica aberta a possibilidade de que apenas uma ou outra dessas inclinaçôes se manifeste, quer dizer, fica em aberto a possibilidade (no sentido moral) de se pensar um indivíduo que se retirasse da sociedade e fosse viver isoladamente, o que corresponderia ao ideal rousseauniano de Robinson Crusoé. Entretanto, como se mostrará a seguir, apesar dessas divergências, as quais talvez impeçam a possibilidade de se falar em sentido forte de uma filiação do conceito kantiano de sociabilidade insociável em relação à obra de Rousseau, por outro lado, estabelecer uma completa cisão é também uma posição insustentável.

\section{A RELAÇÁo ENTRE A SOCIABILIDADE INSOCIÁVEL PARA COM A PIEDADE E O AMOR PRÓPRIO}

As consideraçóes antropológicas de Rousseau se ancoram em algo que Shklar (1985, 33-74) denomina "psicologia moral", isto é, considerações assentadas em uma reflexão introspectiva a qual busca descrever a forma como o "homem em geral" pensa e sente, apresentando aquilo que lhe é natural. ${ }^{23}$ Essa perspectiva possui uma consequência determinante sobre a forma como Rousseau concebe o Estado e como ele projeta as suas instituiçóes. Na medida em que essa psicologia moral se constitui, na obra de Rousseau, como o cerne que permite pensar o desdobramento histórico, é importante retomar os seus principais elementos e sua vinculação com o seu projeto político-pedagógico.

O primeiro elemento é o sentimento de piedade, o qual é "um sentimento natural que, moderando em cada indivíduo a ação do amor de si mesmo, contribui para a conservação mútua de toda a espécie. É ela que nos leva, sem reflexão, socorrer aqueles que vemos sofrer; é ela que, no estado de natureza, ocupa o lugar das leis, dos costumes e da virtude." (ROUSSEAU, 2013, p. 72 / III, 156). A piedade é o primeiro sentimento relativo que toca o coração humano. Todavia, para que a criança se torne sensível e piedosa, é preciso que ela

\footnotetext{
${ }^{23}$ De forma semelhante, ver também Dent (1988, p. 13, traduçấo nossa): "para Rousseau, o desenvolvimento moral e psicológico do caráter do indivíduo particular possui tanto um fundamental interesse quanto um fundamental papel determinante, em relação ao restante da obra. A isso eu também adiciono agora que, para Rousseau, o desenvolvimento do indivíduo e do caráter precisam incluir necessariamente avaliaçôes de outros e o envolvimento com outros indivíduos, os quais são tomados e compreendem um componente essencial da forma e do conteúdo de muitos princípios e disposiçôes constitutivos do próprio indivíduo. ['Quando ele começa a sentir seu ser moral, ele deve estudar a si mesmo na relação com os outros' (Rousseau, Emílio)].”
} 
saiba que existem seres semelhantes a ela que sofrem o que ela sofreu, que sentem as dores que ela sentiu e outras que deve ter ideia de que também poderá sofrer. [...] Só sofremos na medida em que julgamos que ele sofre; não é em nós, mas nele que sofremos; Assim, ninguém se torna sensível a não ser quando sua imaginaçáo se excita e começa a transportá-lo para for de si. (ROUSSEAU, 2014, p. 304 / IV, 505s).

No Emílio, Rousseau apresenta três máximas que sintetizam os diferentes aspectos envolvidos na piedade e como ela se estrutura no contexto do convívio social. Primeira, "não pertence ao coração humano colocar-se no lugar de pessoas mais felizes do que nós, mas apenas no lugar das que estão em situação mais lastimável." (ROUSSEAU, 2014, p. 305 / IV, 506). Segunda, "só lamentamos no outro os males de que não nos acreditamos isentos." (ROUSSEAU, 2014, p. 305 / IV, 507). É por isso que os reis são impiedosos, os ricos são duros para com os pobres e a nobreza despreza o povo, afinal, um rei sabe que nunca será um homem comum, o rico não tem medo de empobrecer e o nobre nunca será um plebeu. Terceira máxima, a "piedade que se tem pelo mal de outrem não se mede pela quantidade desse mal, mas pelo sentimento que atribuimos aos que o sofrem." (ROUSSEAU, 2014, p. 307 / IV, 508). Por isso, "os ricos consolam-se do mal que fazem aos pobres supondo-os bastante estúpidos para sentir. [...] É natural que não se dê muito valor à felicidade das pessoas que se desprezam." (ROUSSEAU, 2014, p. 308 / IV, 509).

Em função dessas três máximas, conclui-se que esse sentimento de piedade é sentido, quando se contempla uma situação de sofrimento específica da qual se pode participar de alguma forma, sendo que ela se refere de um modo muito fraco e insuficiente a uma situação abstrata, como, por exemplo, ao sofrimento da humanidade em geral. ${ }^{24}$

\footnotetext{
${ }^{24}$ Cf. "Parece que o sentimento de humanidade se evapora e enfraquece, quando abraça toda a humanidade; parece que não podemos ser afetados pelas calamidades ocorridas entre os tártaros ou no Japão do mesmo modo como nos afetam as que ocorrem nas naçóes da Europa. Para torná-lo ativo é necessário limitar em alguma medida o nosso interesse e a nossa compaixáo. Como esse sentimento só pode ser útil para aqueles com quem temos que conviver, é apropriado que nossa humanidade concentrada nos concidadáos receba um novo estímulo com o hábito de vê-los, e devido aos interesses comuns que os unem." (ROUSSEAU, 2003c, p.17s./ III, 254s). Cf. "Para que as condiçóes da justiça comum sejam experienciadas como, de fato, estabelecendo aquilo que alguém busca alcançar e considera mais valioso, precisa-se perceber os recebedores da sua justiça como objetos de cuidado e afeição. A última é um fenômeno primário e precisa ter um fundamento preparado de experiências, perspectivas e gostos compartilhados. [...] É isso que faz com que Rousseau argumente que o melhor estado deve ser pequeno, integrado culturalmente, tanto quanto possível autossuficiente e não obrigado por outros estados por carências econômicas." (DENT, 1988, p. 222).
} 
Pode-se sustentar, assim, que é exatamente pela existência de carências e de sofrimentos que surge o sentimento de piedade, fazendo com que os homens se tornem sociáveis. $\mathrm{Ou}$, ainda, a piedade é o sentimento que possibilita e fomenta a sociabilidade humana:

A fraqueza do homem torna-o sociável e nossas misérias comuns levam nossos coraçóes à humanidade; nada lhe deveríamos se não fôssemos homens. Todo apego é sinal de insuficiência; se cada um de nós não tivesse nenhuma necessidade dos outros, náo pensaria em unir-se a eles. Assim, de nossa mesma imperfeição nasce nossa frágil felicidade. [...] Segue-se daí que nos apegamos a ossos semelhantes menos pelo sentimento de seus prazeres do que pelo de seus sofrimentos, pois vemos muito melhor nisso a identidade de nossas naturezas e as garantias do seu apego por nós. (ROUSSEAU, 2014, p. 301 / IV, 503).

O segundo elemento se refere ao amor próprio. "Amor-próprio" é um conceito central, mas também um dos mais difíceis de serem apreendidos. Em primeiro lugar, é preciso distinguir o amor de si do amor próprio. $\mathrm{O}$ primeiro, isto é, o amor de si,

é um sentimento natural que leva todo animal a zelar pela própria conservação e que, dirigido no homem pela razão e modificado pela piedade, produz a humanidade e a virtude. $\mathrm{O}$ amor próprio não é senão um sentimento relativo, artificial e nascido na sociedade, que leva cada indivíduo a dar mais importância a si do que a qualquer outro, que inspira aos homens todos os males que se fazem mutuamente e que é a verdadeira fonte da honra. (ROUSSEAU, 2013, p. 151s / III, 219).

Apesar da diferença entre os dois sentimentos, para Rousseau, o amor próprio se origina do amor de si. ${ }^{25}$ Assim, se todas as outras paixôes do ser humano se originam do amor de si, o qual é em si mesmo bom, ou ainda se "nossas paixôes naturais são muito limitadas" e se "são os instrumentos de nossa liberdade" que "tendem a nos conservar", entâo, "todas as paixôes que nos subjugam e nos destroem vêm-nos de outra parte; a natureza não no-las dá, apropriam-nos delas à sua revelia." (ROUSSEAU, 2014, p. 287 / IV, 491). Portanto, embora

${ }^{25}$ Cf. "A fonte de nossas paixôes, a origem e o princípio de todas as outras, a única que nasce com o homem e nunca o abandona enquanto ele vive é o amor de si; paixão primitiva, inata, anterior a todas as outras e de que todas as outras nâo passam, em certo sentido, de modificaçôes. [...] $\mathrm{O}$ amor de si é sempre bom e sempre conforme a ordem. Estando cada qual encarregado da sua própria conservaçáo, o primeiro e mais importante de seus cuidados é e deve ser zelar por ela continuamente." (ROUSSEAU, 2014, p. 288 / IV, 491). 
diferentes, o amor próprio surge do amor de si, a partir de um longo processo que demanda convivência e comparação com outros indivíduos.

Para Shklar (1985, p. 35), o amor-próprio pode ser compreendido como "o desejo pela desigualdade", que funciona também como "origem e suporte da desigualdade" (SHKLAR, 1985, p. 82), isto é, trata-se do desejo de ser preferido pelos outros mais do que eles próprios se preferem. ${ }^{26}$ Já Dent (1988, p. 52-85) sugere fazer uma diferença entre o "amor-próprio" e o "amor-próprio inflamado"; nesse caso, o primeiro seria uma paixão que surge nas relaçóes sociais, mas pode ter um aspecto moral positivo, enquanto o último seria a fonte das mazelas que o homem padece em sociedade. Ainda que haja muitas nuances que aqui não podem ser exploradas, pode-se dizer que, na vida em sociedade, é impossível que o amor-próprio não surja. ${ }^{27}$ A questão, por conseguinte, é como lidar com ele, a fim de que não produza efeitos necessariamente ruins. De todo modo, é preciso cuidado, pois o "amor-próprio é um instrumento útil, mas perigoso; não raro fere a mão que dele se serve e raramente faz o bem sem mal.” (ROUSSEAU, 2014, p. 340 / IV, 536).

Dessa forma, o amor-próprio no contexto da virtude cívica deve ser pensado como atuando em vários âmbitos, dos quais cabe aqui sublinhar três: primeiro, o amor-próprio bem conduzido serve para a superação da ociosida$\mathrm{de}^{28} \mathrm{e}$ da preguiça, impulsionando o homem à atividade, através da busca pelo orgulho $^{29}$ nas realizaçóes do seu trabalho e na independência da sua pátria; segundo, deve-se dificultar ao máximo que o trabalho seja conduzido para as

\footnotetext{
${ }^{26}$ Cf. "O amor de si, que só a nós mesmos considera, fica contente quando nossas verdadeiras necessidades são satisfeitas, mas o amor-próprio, que se compara, nunca está contente nem poderia estar, pois esse sentimento, preferindo-nos aos outros, também exige que os outros prefiram-nos a eles, o que é impossível. Eis como as paixóes doces e afetuosas nascem do amor de si, e como as paixóes odientas e irascíveis nascem do amor-próprio." (ROUSSEAU, 2014, p. 289 / IV, 493).

${ }^{27}$ Cf. "Pensai que tâo logo o amor-próprio se desenvolve, o eu relativo entra em jogo constantemente e nunca um jovem observa os outros sem se voltar para si mesmo e comparar-se com eles." (ROUSSEAU, 2014, p. 337 / IV, 534).

${ }^{28}$ Cf. "Portanto, trabalhar é um dever indispensável para o homem social. Rico ou pobre, poderoso ou fraco, todo cidadáo ocioso é um patife." (ROUSSEAU, 2014, p. 262 / IV, 470).

${ }^{29}$ Cf. "O termo 'vaidade' não está bem escolhido, por que ela não é mais do que um dos aspectos do amor próprio. Preciso me explicar: a opiniáo que valoriza muito os objetos frívolos produz a vaidade; a que focaliza os objetos importantes e belos em si mesmos produz o orgulho. Assim, pode-se tornar um povo orgulhoso ou vão conforme a escolha dos objetos para os quais dirige os seus julgamentos. $\mathrm{O}$ orgulho é mais natural do que a vaidade, porque consiste em estimar bens verdadeiramente estimáveis, enquanto a vaidade, valorizando o que não tem valor, é obra dos preconceitos." (ROUSSEAU, 2003a, p. 218s./ III, 937s).
} 
atividades comerciais e para a acumulação de riquezas, ${ }^{30}$ sendo que os homens devem ser levados a trabalhar na agricultura, porque ela os torna fortes, saudáveis e bons soldados para servir e proteger a pátria; ${ }^{31}$ terceiro, deve-se evitar ao máximo o ensino e a estima pública das ciências e das artes, ${ }^{32}$ pois elas não foram feitas para o povo e só servem para estender guirlandas de flores sobre as cadeias de ferros que aprisionam os homens. ${ }^{33}$ Assim, uma das formas de evitar

${ }^{30}$ Cf. "A Suíça só se sentiu pobre quando o dinheiro começou a circular, criando no patrimônio das pessoas a mesma desigualdade existente nos recursos. [...] extinguiu-se em todos os coraçóes o amor à pátria, substituído pelo amor ao dinheiro. Superados todos os sentimentos que fortalecem o espírito, não se viu mais nem firmeza na conduta pessoal nem vigor nas decisōes tomadas." (ROUSSEAU, 2003b, p. 195s. / III, 916). "Quanto mais necessário é o dinheiro para os particulares, mais o é igualmente para o governo. Assim, quanto mais florescente o comércio, maiores os impostos, e para pagá-los de nada vale que o camponês cultive a terra, se não consegue vender o que produz. [...] Em consequência, os campos se despovoam e as cidades se enchem de vagabundos; aos poucos começa a faltar o pão, aumenta a miséria pública, acompanhada da opulência dos ricos e aos poucos se acumulam todos os vícios que causam por fim a ruína das naçóes. Considero todo o sistema de comércio como destrutivo da atividade agrícola, e não excetuo nem mesmo o comércio dos produtos da agricultura." (ROUSSEAU, 2003b, p.199s. / III, 920). "Vê-se assim que se o uso do dinheiro não pode ser totalmente eliminado nos negócios particulares, pelo menos pode ser reduzido de tal forma que dificilmente levará a abusos; por esse meio não serão reunidas fortunas, e quando isto ocorrer, elas serão quase inúteis, trazendo poucos benefícios aos seus detentores." (ROUSSEAU, 2003b, p. 209 / III, 929).

31 "Lavrar o solo torna os homens pacientes e robustos, qualidades necessárias para fazer bons soldados. Os recrutas colhidos nas cidades são frouxos e indisciplinados; não podem suportar as fadigas da guerra; esfalecem sob a tensão das longas marchas; são consumidos pela doença; disputam entre si e fogem do inimigo. As milícias treinadas são os melhores soldados, e mais confiáveis. A verdadeira formação de um soldado é trabalhar no campo. A agricultura é o único meio de manter a independência externa de um Estado." (ROUSSEAU, 2003b, p.184 / III, 905). "Numerosas famílias bem nutridas e bem vestidas honrarão os chefes e como a abundância real é o único objeto de luxo, todos desejarão distinguir-se por ele. Enquanto o coração humano permanecer o que ele é, essas instituições não deverão provocar a preguiça." (ROUSSEAU, 2003b, p.205s. / III, 925).

32 Cf. "É a razão que engendra o amor-próprio e a reflexão o fortifica; faz o homem voltar-se sobre si mesmo; separa-o de quanto o perturba e aflige. É a filosofia que o isola; por sua causa, diz ele, em segredo, ao ver um homem sofrendo: 'Perece, se queres; quanto a mim, estou seguro'. Nada, além dos perigos da sociedade inteira pode atrapalha o sono tranquilo do filósofo e o arranca do seu leito." (ROUSSEAU, 2013, p. 71s / III, 156). "Deve-se afastar também com cuidado as artes do ócio, as artes que levam à vida fácil e confortável, favorecendo as que são úteis à agricultura e benéficas à vida do homem. Não precisamos de escultores ou de ourives, mas sim de carpinteiros e ferreiros, tecelóes, bons trabalhadores em lã e não bordadeiras ou artesãos que trabalhem o ouro." (ROUSSEAU, 2003a, p.206 / III, 926).

${ }^{33}$ Cf. ROUSSEAU, 1973, p. 343 / III, 07. Ver também: "Se é preciso permitir a alguns homens entregarem-se ao estudo das ciências e das artes, isso só se fará com aqueles que se sentirem com forças para andarem sozinhos em suas sendas e ultrapassá-las; é a esse pequeno número que cabe elevar monumentos de glória do espírito humano." (ROUSSEAU, 1973, p. 359 / III, 29) E ainda: "É a confusão do comércio e das artes, é o ávido interesse do ganho, é a lassidão e o amor das comodidades que transformam os serviços pessoais em dinheiro. Cede-se parte do lucro para aumentá-lo à vontade. Daí dinheiro e logo tereis grilhôes. A palavra Finança é uma palavra de escravo, é desconhecida na Cidade." (ROUSSEAU, 1999, p. 113/ III, 429). 
que o amor próprio se transforme em um amor próprio egoísta e inflamado é através da condução dessa paixão para algo maior, para o amor à pátria. ${ }^{34}$

Já da perspectiva da virtude moral, o amor próprio deve ser sempre controlado pela razão e pela consciência, de modo que ele não assuma o controle da vida do indivíduo. Nas palavras de Rousseau (2014, p. 657 / IV, 819):

Trata-se de um erro separar as paixões entre as permitidas e as proibidas, para entregar-se às primeiras e recusar-se às outras. Todas são boas quando permanecemos senhores delas, e todas são más quando nos deixamos subjugar por elas. O que nos é proibido pela natureza é estender nossos apegos para além de nossas forças; o que nos é proibido pela razão é querer o que não podemos obter; o que nos é proibido pela consciência não é sermos tentados, mas sim deixar-nos vencer pelas tentaçôes. Não depende de nós ter ou não ter paixóes, mas depende de nós reinar sobre elas. Todos os sentimentos que dominamos são legítimos; todos os que nos dominam são criminosos.

Em suma, para Rousseau, utilizando-se de uma analogia, o objetivo da educação tanto civil quanto moral é semelhante ao trabalho de deslocamento do curso de um rio. Não se trata de represá-lo ou de diluí-lo, pois, uma vez que o homem vive em sociedade e o surgimento do amor-próprio é inevitável, cabe apenas deslocar o seu curso, para que ele não se direcione para o egoísmo ou para o amor próprio inflamado e sim para o interesse comum e para a virtude moral.

${ }^{34} \mathrm{Cf}$. "Apesar de toda a complexidade, as respostas de Rousseau se reduzem a uma fórmula simples. O amor-próprio é bom quando ele estende e aprofunda a existência e mal quando ele faz o oposto. Amor-próprio pode estender e aprofundar a existência em uma das seguintes três formas: pelo cidadão, pelo homem natural não-civilizado e pelo homem natural que vive no interior do estado civil. $\mathrm{O}$ que cada um desses tipos tem em comum é um interior completo. Em cada um deles, o amor-próprio não possui contradição interna; eles estão imaculados pelo conflito entre natureza e sociedade, isto é, entre inclinaçáo e dever. Essa completude interna une esses homens como exemplares da vida boa. $\mathrm{O}$ que os distingue uns dos outros é o caráter particular da completude. O amor-próprio do cidadão é exclusivamente um patriotismo social; claro que ele tem um amor individual para consigo, mas ele se ama enquanto cidadão, com uma parte de um todo maior e assim ele não sofre qualquer diminuição da sua existência por uma contradição interna. $\mathrm{O}$ amor-próprio do homem natural nâo civilizado, seja ele o habitante primitivo do estado de natureza ou o estranhamente desenvolvido (ou 'pós-civilizado) Jean-Jacques, retém seu caráter original e, com isso, sua bondade original. O amor-próprio do homem natural no estado civil é o mais complexo. Diferente dos outros exemplos, Emílio possui ambos o amor de soi e o amour-propre na sua alma. Enquanto os outros dois tipos 'resolvem' a contradiçâo entre natureza e sociedade escolhendo uma ou outra, Emílio consegue reconciliar natureza e sociedade, o amor de soi e o amour-propre, ao alcançar uma aliança entre eles." (COOPER, 1999, p. 171, tradução nossa). 
Uma visão semelhante é defendida por Kant, o qual afirma que "com violência nada se conseguiu contra a sensibilidade nas inclinaçóes; é preciso ludibria-las e, como diz Swift, dar um tonel para a baleia brincar, a fim de salvar o navio." (KANT, Anth. AA 07: 152). Ademais, para Kant, não cabe eliminar as inclinaçóes ou sentimentos que constituem a natureza humana, mas compreendê-los e conduzi-los. Esse tópico é amplamente abordado no contexto do conceito da sociabilidade insociável:

O meio de que a Natureza se serve para levar a cabo o desenvolvimento de todas as disposiçôes é o antagonismo das mesmas na sociedade, na medida em que este se torna finalmente causa de uma ordem legal dessas mesmas disposiçōes. Entendo aqui por antagonismo a sociabilidade insociável dos homens, isto é, a sua tendência para entrarem em sociedade, tendência que, no entanto, está unida a uma resistência universal que ameaça dissolver constantemente a sociedade. Esta disposição reside manifestamente na natureza humana. (KANT, IaG, AA 08: 20).

O antagonismo das disposições representa a atuação de duas tendências com sentidos contrários. De um lado, a inclinação (Neigung) para se socializar (vergesellschaften), de outro, uma propensão (Hang) para se isolar (vereinzelnen). A sociabilidade é caracterizada como "uma inclinação para entrar em sociedade, pois em semelhante estado o homem se sente mais como homem, isto é, sente o desenvolvimento das suas disposições." (KANT, IaG, AA 08: 20f.). Conforme Kant, o homem se encontra destinado para a sociedade e sente um impulso para entrar nela, porque é somente ali que ele consegue satisfazer adequadamente suas necessidades, ${ }^{35}$ desenvolver o seu gosto pela beleza (KANT, KU, AA 05: 296f.; 355) e saciar seu intenso desejo de compartilhar pensamentos e sentimentos (KANT, MS 06: 471f. / KU, AA 05: 296f). Também é apenas em sociedade que ele consegue alcançar a corretude do pensar (KANT, WDO, AA 08: 144). Em suma, pode-se sustentar que a tendência à socialização é, no fundo, a tendência do homem a efetivar a sua natureza, um impulso para transformar sua natureza rationabile numa natureza rationale,

\footnotetext{
${ }^{35}$ Cf. "O ser humano está destinado, por sua razão, a estar numa sociedade com seres humanos e a se cultivar, civilizar e moralizar nela por meio das artes e das ciências." (KANT, Anth AA 07: 324); e também em KANT, MAM AA 08: 110. Além disso, cf. "O homem possui o impulso distintivo de querer se valorizar frente aos seus iguais (ou na aparência através do medo, ou do respeito através da admiração ou da simpatia através do amor), pois o seu bem viver depende não apenas de si próprio, mas da ajuda de outros seres humanos. Sem a sociedade ele não se basta a si mesmo. Tudo é finalmente direcionado para seu sustento, conveniência e amor." (KANT, Refl 1452, 15: 634, n., tradução nossa).
} 
dominando suas faculdades racionais, epistemológicas, morais e estéticas, as quais se encontram nele apenas em gérmen (KANT, Anth, AA 07: 321f).

Já a insociabilidade se configura como uma propensão ao isolamento, pois se sustenta sobre a propriedade de cada homem de "querer dispor de tudo ao seu gosto" (KANT, Ia G, AA 08: 21), isto é, de querer exercer sua vontade sobre os demais. Isso faz com que o homem espere resistência de todos os lados, tal como sabe por si mesmo que, da sua parte, sente inclinação para exercitar a resistência contra os outros, ou seja, de evitar que sua vontade seja submetida à vontade de outrem. ${ }^{36}$

Analisando o texto da $I a G$, encontram-se indicaçóes de quais seriam os impulsos que caracterizam a propensão insociável do ser humano. Kant enfatiza que o homem é "movido pela ambição, tirania e ganância, para obter uma posição entre os seus congêneres, que ele não pode suportar, mas de que também não pode prescindir." (KANT, $I a G$, AA 08: 21$)^{37}$. Um pouco mais à frente, ele continua: "Graças, pois, à Natureza pela incompatibilidade, pela invejosa e competitiva vaidade, pelo apetite insaciável de posses ou também para a dominação! Sem elas, todas as excelentes disposiçóes naturais da humanidade dormiriam sem desabrochar." (KANT, IaG, AA 08: 21).

Assim, de um lado, sem as propriedades da insociabilidade, embora elas não sejam em si mesmas dignas de apreço, todos os talentos e disposiçóes permaneceriam para sempre dormentes e os homens imersos na indolência e "tão bons como as ovelhas que eles apascentam, dificilmente proporcionariam a esta sua existência um valor maior do que o que tem este animal doméstico; não cumulariam o vazio da criação em vista do seu fim, como seres de natureza racional." (KANT, IaG, AA 08: 21). De outro lado, sem a tendência à sociabilidade, o ser humano viveria em isolamento, talvez em pequenas famílias.

\footnotetext{
${ }^{36}$ Veja-se esta formulação mais tardia: "o que subministra esta garantia [da paz perpétua] é nada menos que a grande artista, a Natureza (natura daedala rerum), de cujo curso mecânico transparece com evidencia uma finalidade: através da discórdia dos homens, fazer surgir a harmonia, mesmo contra sua vontade." (KANT, ZeF, AA 08:360). Insociabilidade ou discórdia são apenas nomes distintos para se referir a uma mesma coisa: uma determinada constituiçáo do ser humano "de querer dispor de tudo segundo a sua vontade".

${ }^{37}$ A tradução de Ehrsucht, Herrschsucht e Habsucht não é simples. Artur Morão traduz simplesmente por ânsia de honras, de poder e de posses; Clélia Martins, em sua tradução da Antropologia, de um ponto de vista pragmático, opta por ambiçấo, desejo de dominação e cobiça. Contudo, penso que uma tradução conceitualmente mais aproximada e, ao mesmo tempo, estilisticamente melhor, seria: ambição, tirania e ganância, pois "tirano" já indica alguém dominado pela paixão pelo poder, enquanto "ganância" parece se dirigir mais claramente a bens materiais do que "cobiça", que parece ter um campo semântico mais abrangente.
} 
Contudo, os indivíduos seriam movidos por sentimentos misantrópicos ou antropofóbicos, pois os outros seres humanos seriam vistos apenas como inimigos, em parte grosseiros, em parte desprezíveis.

Se compararmos a maneira como Rousseau compreende o sentimento de piedade e a forma como Kant caracteriza a sociabilidade, é possível perceber um núcleo consideravelmente semelhante representado na ideia de uma tendência natural para aproximação dos seres humanos, algo que surge exatamente da condição de carência do ser humano. Ambos os filósofos (pelo menos o Rousseau do Emílio) pensam que o ser humano somente consegue satisfazer minimamente a sua condição, unindo-se a outros. É a necessidade que conduz a sociabilidade e a humanidade, porque é apenas em sociedade que o homem pode se colocar como um ser moral (no sentido positivo).

De modo semelhante, ao se analisar a compreensão que ambos os filósofos desenvolvem acerca da insociabilidade ou do amor próprio, novamente aqui se encontram algumas congruências dignas de destaque. Segundo Kant, assim como para Rousseau, todos os males resultantes da insociabilidade não resultam da insociabilidade per se, isto é, das tendências de querer que as coisas sigam bem para si mesmo, algo que seria fruto do amor de si, mas são, de fato, desdobramentos resultantes do amor próprio, o qual transforma as inclinaçôes inerentes ao amor de si (algo que em si mesmo é bom) em algo mau, isto é, em algo que corrompe a disposição moral. ${ }^{38}$ Isso pode ser observado no excerto abaixo:

Todas as inclinações em conjunto (que certamente podem também ser compreendidas em um razoável sistema e cuja satisfação chama-se então felicidade própria) constituem o solipsismo [Selbstsucht] (Solipsismus). Este consiste ou no solipsismo do amor de si [Selbstliebe], como uma benevolência [Wohlwollens] para consigo mesmo sobre todas as coisas (philautia), ou no solipsismo da complacência [Woblgefallens] em si mesmo (arrogantia). Aquele se chama especificamente amor próprio [Eigenliebe] e este presunção [Eigendünkel]. A razão prática pura apenas causa dano ao amor próprio [Eigenliebe] na medida em que ela o limita - enquanto natural e ativo em nós ainda antes da lei moral - apenas à condição da concordância com esta lei, em cujo caso entáo ele denomina-se amor de si racional [vernünftige Selbstliebe]. Mas ela com certeza abate a presunção [Eigendünkel], na medida em que todas as exigências de auto-estima que precedem a concordância com a lei moral são nulas e totalmente ilegítimas. (KANT, $K p V$, AA 05: 73).

\footnotetext{
${ }^{38}$ Sobre uma análise detalhada acerca do conceito de sociabilidade insociável e de como ela não pode ser equiparada com o mal, ver meu artigo (KLEIN, 2013b).
} 
Note-se que o amor de si (Selbstliebe) pode encontrar uma concordância com a lei moral e, portanto, pode ser política e moralmente aceito e estimulado. Por outro lado, é exatamente o solipsismo do amor de si, quer dizer, o fechamento na exclusividade do eu, que se transforma em amor próprio (Eigenliebe). Em uma reflexão, lê-se: “Todas as inclinações são exclusivas ou inclusivas. As primeiras são úteis para si mesmo, as outras são úteis a todos. $\mathrm{O}$ amor de si e a autoconsideração são por sua natureza não exclusivas, mas o amor próprio e a presunção o são." (KANT, Refl, AA 20: 183, tradução nossa). ${ }^{39}$

No texto da Religiáo nos limites da simples razão, Kant retoma essa caracterização do amor de si. Mas, nesse caso, cabe apontar para uma diferença com relação a Rousseau, qual seja, que, para Kant, o amor de si já envolve uma comparação e não se relaciona apenas para consigo mesmo. Contudo, é ainda sempre uma comparação em si mesma produtiva e boa:

As disposiçóes para a humanidade podem referir-se ao título geral do amor de si, sem dúvida, físico, mas que compara [vergleichenden Selbstliebe] (para o que se exige razáo), a saber: julgar-se ditoso ou desditado só em comparação com outros. Do amor de si promana a inclinação para obter para si um valor na opiniāo dos outros; e originalmente, claro está, apenas o da igualdade: não conceder a ninguém superioridade sobre si, juntamente com um constante receio de que outros possam a tal aspirar; daí surge gradualmente um desejo injusto de adquirir para si essa superioridade sobre outros. [...] a natureza só queria utilizar a ideia de semelhante emulação (que em si não exclui o amor recíproco [der an sich die Wechselliebe nicht ausschließt]) como móbil da cultura. (KANT, RGV, AA 06: 27).

Essa leitura positiva do amor de si, o qual se estabelece na relação com outros indivíduos, mas não é exclusivo e, por conseguinte, não é solipsista, também aparece de modo bastante claro na Metafísica dos costumes:

Chama-se modéstia [Bescheidenheit] à moderação nas pretensões em geral, quer dizer, a restrição voluntária do amor a si próprio [Selbstliebe], ao ter em conta o amor a si próprio alheio [Selbsliebe Anderer]. A falta desta moderação (imodéstia) em relação à dignidade de ser amado por outros chama-se amor próprio [Eigenliebe] (philautia). (KANT, MS, AA 06: 462).

\footnotetext{
${ }^{39}$ Nesse mesmo sentido, lê-se: "O sistema de Epiruco é um princípio do amor de si [Selbsliebe], uma palavra que utilizamos para conceituar tanto a utilidade quanto a honra. No entanto, nós usamos também essa mesma expressão para distingui-la do amor próprio [Eigenliebe], pois este é um amor exclusivo, mas, para Epicuro, o amor de si é também fundamento para o amor aos outros e não é exclusivo, mas expande a nossa amizade." (KANT, Refl. 6894, AA 19: 198, tradução nossa).
} 
É exatamente por que o amor de si é inerente à natureza humana e legítimo em si mesmo que Kant sustenta sobre ele um argumento em favor do dever da promoção da felicidade alheia. ${ }^{40}$ Ora, nota-se que, de acordo com Kant, a insociabilidade é, na verdade, o resultado inerente da existência do amor de si, o qual, uma vez que não seja conduzido de acordo com os princípios da razão, pode se tornar solipsista, degenerar em paixóes e, nesse caso, no mal. Entretanto, a insociabilidade não é em si mesma solipsista e, por conseguinte, um mal.

É exatamente por que a sociabilidade insociável se enraíza na constituição antropológica do homem, de tal modo que se pode dizer que essa característica é inerente à sua natureza, que não cabe a nenhum projeto político ou moral tentar extirpá-la. Cabe apenas controlá-la, de maneira que ela possa continuar conduzindo o processo de desenvolvimento social e civil, mas sempre com o cuidado para que a insociabilidade não degenere no amor-próprio e em todos os males que assolam a sociedade e a espécie. Isso é possível, na medida em que a sociabilidade insociável deve ser posta dentro dos limites adequados da "cerca do direito civil", o que constitui, tanto para Rousseau quanto para Kant, a instituição de uma República (a despeito de cada um entender, nesse conceito, particularidades próprias), isto é, de um Estado justo regido por leis. ${ }^{41}$

Em suma, a partir do que foi mostrado acima, parece ficar inconteste o quanto a concepção antropológica de Rousseau influenciou as reflexóes kantianas acerca da natureza humana. Entretanto, como também indicado, a postura de Kant não é a de um simples herdeiro, pois ele faz questão de reconfigurar conceitos e modificar perspectivas, de tal sorte que a antropologia kantiana não pode ser vista como sendo simplesmente uma retomada daquela de Rousseau, ainda que lhe seja amplamente devedora ${ }^{42}$.

\footnotetext{
${ }^{40} \mathrm{Cf}$. "Que esta beneficência é um dever decorre do seguinte: de que, uma vez que o nosso amor por nós mesmos [unsere Selbstliebe] não pode separar-se da necessidade de ser amados também por outros (ser ajudados em caso de necessidade), convertemo-nos a nós próprios em fins de outros, e, dado que esta máxima não pode obrigar senáo meramente pela sua qualificaçáo para se converter em lei universal, por conseguinte, de tornar outros também em fins para nós, a felicidade alheia é um fim que é simultaneamente um dever." (KANT, MS, AA 06: 393).

${ }^{41}$ Sobre o conceito kantiano de República, ver meu artigo (KLEIN, 2016). Sobre a perspectiva republicana de Rousseau, ver o texto de Klein e Consani (2017a).

${ }^{42}$ Sobre o modo como a comparação entre as concepçôes antropológicas de ambos os filósofos impacta nas suas respectivas concepçōes de política, ver o artigo de Klein e Consani (2017b).
} 
KLEIN, J. T. The question of human nature: Kant, a reader of Rousseau. Trans/form/ação, Marília, v. 42, n. 1, p. 9-34, Jan./Mar., 2019.

ABSTRACT: This paper analyses the influence of Rousseau's philosophy on Kant's anthropological theory. Firstly, the similarities and differences between each philosopher's understanding of the state of nature is presented. Secondly, a comparison between Kant's concept of unsocial sociability and Rousseau's concepts of piety and self-love is presented.

KEYwOrDs: Kant. Rousseau. Anthropology. Human nature.

\section{REFERÊNCIAS}

ARISTÓTELES. Política. Tradução de Mário da Gama Kury. Brasília: Editora da Universidade de Brasília, 1997.

COOPER, L. D. Rousseau, nature, and the problem of the good life. Pennsylvania: Pennsylvania State University Press, 1999.

DENT, N. J. H. Rousseau: an introduction to his psychological, social and political theory. New York: Basil Blackwell, 1988.

HERDER, J. G. Ideen zur Philosophie der Geschichte der Menschheit. Wiesbaden: Fourier, 1985.

KANT, I. Gesammelte Schriften. Hrsg.: Bd. 1-22 Preussische Akademie der Wissenschaften, Bd. 23 Deutsche Akademie der Wissenschaften zu Berlin, ab Bd. 24 Akademie der Wissenschaften zu Göttingen. Berlin 1900ff.

. Primeira introduçáo à crítica do juizo. Tradução de Rubens Rodrigues Torres Filho. In: Kant II. São Paulo: Abril Cultural, 1980. (Os Pensadores). 70, 1992. A religiáo nos limites da simples razão. Tradução de Artur Morão. Lisboa: Ediçóes

. Crítica da faculdade do juizo. Tradução de Valerio Rohden e António Marques. 2. ed. Rio de Janeiro: Forense Universitária, 2002a.

. Crítica da razão prática. Tradução de Valerio Rohden. São Paulo: Martins Fontes, 2002b.

A paz perpétua. Tradução de Artur Morão. In: A paz perpétua e outros opúsculos. Lisboa: Ediçôes 70, $2004 a$.

. Ideia de uma história universal com um propósito cosmopolita. Tradução de Artur Morão. In: . A paz perpétua e outros opúsculos. Lisboa: Ediçōes 70, $2004 \mathrm{~b}$. 
. Que significa orientar-se no pensamento? Tradução de Artur Morão. In: . A paz perpétua e outros opúsculos. Lisboa: Edições 70, $2004 \mathrm{c}$.

. A metafísica dos costumes. Tradução de José Lamego. Lisboa: Calouste Gulbenkian, 2005.

Antropologia de um ponto de vista pragmático. Traduçáo de Clélia Aparecida Martins. São Paulo: Iluminuras, 2006.

. Inicio conjectural da história humana. Tradução de Joel Thiago Klein. Ethic@, v. 8, n. 1, p. 157-168, 2009.

. Vorlesungen Wintersemester 1775/1776 Friedländer. Tradução de Fernando M.

F. Silva. Estudos Kantianos, Marília, v. 1, n. 1, p. 255-282, jan./jun. 2013. (AA 20).

. Bemerkungen zu den Beobachtung über das Gefühl des Schönen und Erhabenen.

Reflexionen (AA 14-19).

KLEIN, J. T. Kant e a primeira recensão a Herder: comentário, tradução e notas. Studia Kantiana. Rio de Janeiro, v. 13, p. 121-147, 2012.

. Kant e a segunda recensão a Herder: comentário, tradução e notas. Studia Kantiana, Rio de Janeiro, v. 14, p. 190-214, 2013.

. Kant e a ideia de uma história universal. São Paulo: Loyola, 2016.

. A sociabilidade insociável e a antropologia kantiana. Revista de Filosofia, Aurora (PUCPR), v. 25, n. 36, p. 265-285, 2013.

. O Estado republicano democrático e o ensino público da moral segundo Kant. Discurso : Departamento de Filosofia da FFLCH da USP, v. 46, n. 2, p. 85-122, 2016.

CONSANI, C. F. A complementaridade entre os aspectos liberais e republicanos na filosofia política de Rousseau. Veritas, v.62, n. 1, p. 65-97, 2017a.

. A questão da teleologia: Kant leitor de Rousseau. Cadernos de Filosofia Alemá, v. 22 , n. 1, p. 51-70, 2017 b.

ROUSSEAU, J.-J. Discurso sobre as ciências e as artes. Tradução de Lourdes Santos Machado. In: Jean-Jacques Rousseau. São Paulo: Abril Cultural, 1973. (Os Pensadores).

. O contrato social. Tradução de Antonio de Pádua Danesi. São Paulo: Martins Fontes, 1999.

. Consideraçóes sobre o governo da Polônia e sua projetada reforma. In:

Rousseau e as relaçóes internacionais. Tradução de Sérgio Bath. São Paulo: Imprensa Oficial do Estado, 2003a. p. 221-316. 
Projeto de constituição para a Córsega. In: Rousseau e as relaçóes internacionais. Tradução de Sérgio Bath. São Paulo: Imprensa Oficial do Estado, 2003b. p. $177-220$.

. Tratado sobre a economia política. In: Rousseau e as relaçóes internacionais. Tradução de Sérgio Bath. São Paulo: Imprensa Oficial do Estado, 2003c. 1-44.

. Euvres complètes. 5 v. Paris: Gallimard, 2011.

. Discurso sobre a origem e os fundamentos da desigualdade entre os homens. Tradução de Paulo Neves. Porto Alegre: L\&PM Pocket, 2013.

. Emílio, ou, Da educação. Tradução de Roberto Leal Ferreira. 4. ed. São Paulo: Martins Fontes, 2014.

SHKLAR, J. Men and citizens: a study of Rousseau's social theory. Cambridge: Cambridge University Press, 1985.

WEYAND, K. Kants Geschichtsphilosophie: Ihre Entwicklung und ihr Verhältnis zur Aufklärung. Köln: Kölner Universität, $1963 .{ }^{43}$

Recebido: 22/10/2016

Aceito: 15/03/2018 